\title{
Use of cervical inversion technique as a tamponade to control postpartum hemorrhage caused by placenta previa and placenta previa focal accreta
} Article

\author{
Elham H. Madny, Khaled A. Atwa, Aida H. Eid, Mohamed M. Farag
}

Department of Obstetrics and Gynecology, Faculty of Medicine, Suez Canal University Hospital, Suez Canal, Egypt

\begin{abstract}
Aim of the work: To assess the efficacy of cervical inversion as a tamponade in controlling placental bed bleeding in cases of placenta previa and accreta.

Patients and Methods: After approval of ethics committee, a descriptive prospective study was conducted among a total of 40 female pregnant women ( 20 with placenta previa and 20 focal accreta) who attended the inpatient clinic of Obstetrics and Gynecology Department at Suez Canal University Hospital over a period of one year from April 2016 to April 2017. Preoperative assessment via history taking and clinical examination as used per hospital standard protocol with an assessment of hemodynamic stability was performed. Patients were evaluated for time needed for the technique, blood loss and postoperative hospital stay. Six weeks postoperative, follow up assessment of position of cervix by speculum examination was performed.

Results: Mean age of patients was 29.2 years old. Mean time required for technique was 8 minutes and was longer with placenta accreta. Mean intraoperative blood loss was $1340.95 \mathrm{ml}$ with significantly more blood loss with placenta accreta. Speculum examination six weeks postoperatively revealed normal position and normal morphology of the cervix in 32 cases $(80 \%)$.

Conclusion: Cervical inversion as a tamponade is apparently safe, simple, rapid and potentially effective easy to perform procedure.
\end{abstract}

Key Words: Placenta previa, placenta accreta, postpartum

Received: 27 September 2018, Accepted: 11 November 2018

Corresponding Author: Elham H. Madny, Department of Obstetrics and Gynecology, Faculty of Medicine, Suez Canal University Hospital, Egypt, Tel.: 01000552837, E-mail: Elham.madny@yahoo.com.

ISSN: 2090-7265, February 2019, Vol.9, No.1

\section{INTRODUCTION}

There are increasing rates of placenta previa and placenta previa accreta that is - to some extent - related to the currently increasing rates of cesarean section delivery ${ }^{[1,2]}$. Postpartum hemorrhage, a major complication of placenta previa ${ }^{[3]}$ remains the most important cause of maternal mortality that approaches up to $14 \%$ in low income countries ${ }^{[4,5]}$.

The differences between the lower and upper segments of the uterus are the main cause for postpartum hemorrhage associated with placenta previa. The lower uterine segment is highly vascular and slower to retract than upper segment. Surgical intervention is indicated when uterotonic medications fail to control blood loss ${ }^{[6,7]}$.

Several techniques have been described in the literature for controlling massive bleeding associated with placenta previa cesarean sections, including uterine packing with gauze, balloon tamponades, the B-Lynch suture, insertion of parallel vertical compression sutures, a square suturing technique and embolization or ligation of the uterine and internal iliac arteries ; but there is a wide variation in the success rate of these maneuvers ${ }^{[8]}$. Over-sewing of the bleeding site is the most common procedure used for PPH management ; but in many cases, the bleeding points located in the lower segment and cervical canal are too deep and their locations are unclear because of the severity of the bleeding ${ }^{[9]}$.

Suturing an inverted lip of the cervix over the bleeding placental bed was first described at 2007 by Dawlatly and colleagues ${ }^{[10]}$. The current study was conducted to assess the efficacy of cervical inversion as a tamponade in controlling placental bed bleeding in cases of placenta previa and accreta.

\section{PATIENTS AND METHODS}

After approval of Ethics Committee of Faculty of Medicine, Suez Canal University, the present prospective descriptive study was conducted among a total of 40 female pregnant women (20 with placenta previa and 20 focal accreta) who attended the inpatient clinic 
of Obstetrics and Gynecology Department at Suez Canal University Hospital over a period of one year from April 2016 to April 2017. Participants diagnosed with placenta previa and/or placenta previa accreta by ultrasound or MRI whenever ultrasonography is no conclusive, or intraoperative diagnosis of focal (partial) placenta previa accreta were included into the study. Patients with placenta percreta, placenta increta, diffuse placenta accreta or massive or uncontrollable postpartum hemorrhage were excluded from the study. Written informed consent was obtained from all patients with complete explanation about the procedure, the risks including massive postpartum hemorrhage and the need for blood transfusion, the use of conservative methods and the possibility of proceeding to emergency hysterectomy.

Preoperative assessment via history taking and clinical examination as used per hospital standard protocol with assessment of hemodynamic stability was performed.

\section{Technique for cervical tamponade:}

General or spinal anesthesia was administered according to the hemodynamic state of the patient and the opinion of the anesthetic and surgical teams. The patient was placed in a dorsal lithotomy position with hip abduction and flexion to observe the amount of blood loss. Good reflection of the urinary bladder was performed before making the uterine incision. If the placenta separated completely, the placental bed was observed for bleeding and managed accordingly. If the placenta didn't separate at all (diffuse placenta accreta), we proceeded to cesarean hysterectomy. In cases of focal placenta accreta, the remaining portion of the placenta was removed and the placental bed was observed to determine the amount of bleeding and the need for intervention. Excessive bleeding from the placental bed, which soaks more than three towel within a short time with blood seen pouring from the placental bed into the lower uterine segment, was considered significant blood loss that warrants surgical intervention. If the bleeding originated primarily from the anterior portion of the lower uterine segment, the surgeon introduces his/her hand through the uterine incision into the lower uterine segment until it touched the cervix. A long Allis forceps passed through the uterine incision and used to grasp the anterior lip of the cervix, pulling the cervix upwards into the uterine cavity. The anterior lip of the cervix was sutured to the anterior wall of the lower uterine segment using continuous locked absorbable stitches (Vicryl no. 1). This aided to compress the bleeding sites of the placental bed and support the very thin lower uterine segment seen in such cases. If the placenta implanted posteriorly and the bleeding areas were mainly from the posterior wall of the uterus, the same procedure was repeated using the posterior lip of the cervix, which could then be sutured to the posterior wall of the lower uterine segment. A Hegar dilator was inserted in a retrograde manner from the abdominal aspect to ensure patency of the cervical canal during the suturing process. The bleeding was then observed from the abdominal aspect and also vaginally. At the end, the uterine incision was closed in the usual way. The intra-operative blood loss was calculated according to the number of soaked blood towels, by measuring the weight of towel preoperative and postoperative.

\section{Outcome measures:}

Patients were evaluated for time needed for the technique, blood loss and postoperative hospital stay. Six weeks postoperative, follow up assessment of position of cervix by speculum examination was performed.

\section{Statistical analysis:}

Gathered information was processed using SPSS version 25 (SPSS Inc., chiago, IL, USA.). Quantitative data was expressed as means $\pm \mathrm{SD}$, while qualitative data was expressed as number and percentages (\%). Unpaired $t$ test was used to test the significance of difference for quantitative variables and Chi-square was used to test the significance of difference for qualitative variables. A probability value ( $p$-value $<0.05)$ was considered statistically significant.

\section{RESULTS}

The mean age is $29.20 \pm 4.29$ years and mean gestational age is $37.70 \pm 1.09$. Regarding parity, five patients (12.5\%) are primigravida. 26 patients $(65 \%)$ had general anesthesia and 14 patients $(35 \%)$ had spinal anesthesia. $45 \%$ of the studied patients had both lip inverted, 16 patients $(40 \%)$ had anterior lip inverted and 6 patients $(15 \%)$ had posterior lip inverted. The mean time needed to perform the technique was $8.0 \pm 2.44 \mathrm{~min}$ (range: $4-12 \mathrm{~min}$ ) (Table 1). 
Table 1: Baseline characteristics among the studied patients:

\begin{tabular}{lccc}
\hline & & Number & Percentage \\
\hline Age (years) & Mean \pm SD & & $29.20 \pm 4.29$ \\
& Range & & $23-40$ \\
& Mean \pm SD & & \\
Gestational age (weeks) & Range & & $37.70 \pm 1.09$ \\
& NP & $35-40$ & $12.5 \%$ \\
Parity & P1-2 & 5 & $45 \%$ \\
& P 3 & 18 & $42.5 \%$ \\
Previous CS & No & 17 & $20 \%$ \\
& Yes & 8 & $80 \%$ \\
Type of anesthesia & Spinal & 32 & $35 \%$ \\
& General & 14 & $65 \%$ \\
Inverted cervical lip & Anterior & 26 & $40 \%$ \\
& Posterior & & $15 \%$ \\
\end{tabular}

Mean intra-operative blood loss is $1340.95 \mathrm{~mL}, 21$ patients $(52.5 \%)$ had not received blood transfusion, 19 patients had received blood transfusion $(47.5 \%)$ and the mean number of blood units transfused is $1.58 \pm 0.84$. The postoperative complications encountered were as follows: bladder injury in the two patients, hysterectomy in two patients and postoperative fever that responded to antibiotics occurred in three patients. The mean duration of the postoperative hospital stay was $3.05 \pm 1.26$ days.
Speculum examination revealed normal position and normal morphology of the cervix in 32 cases $(80 \%)$. In four patients, the cervix was displaced upwards $(10 \%)$; in one patient, the cervix was taken high with difficult accessibility $(2.5 \%)$ and in the other three patients, the crevices were taken high but with easy accessibility (7.5\%), two patients had not attend the follow up $(5 \%)$ and two patients had hysterectomy $(5 \%)$ (Table 2).

Table 2: Outcome measures among both the studied patients:

\begin{tabular}{|c|c|c|c|c|}
\hline & & Number & & Percentage \\
\hline Time needed to technique (min) & $\begin{array}{c}\text { Mean } \pm \mathrm{SD} \\
\text { Range }\end{array}$ & & $\begin{array}{c}8 \pm 2.44 \\
4-12\end{array}$ & \\
\hline Intra-operative blood loss & $\begin{array}{c}\text { Mean } \pm \mathrm{SD} \\
\text { Range }\end{array}$ & & $\begin{array}{c}1340.95 \pm 214.01 \\
1066-1698\end{array}$ & \\
\hline Blood transfusion & $\begin{array}{l}\text { No } \\
1-2 \text { units } \\
3-4 \text { units }\end{array}$ & $\begin{array}{l}21 \\
17 \\
2\end{array}$ & & $\begin{array}{c}52.5 \% \\
42.5 \% \\
5 \%\end{array}$ \\
\hline Complications & $\begin{array}{c}\text { None } \\
\text { Bladder injury } \\
\text { Fever } \\
\text { Hysterectomy }\end{array}$ & $\begin{array}{c}33 \\
2 \\
3 \\
2\end{array}$ & & $\begin{array}{c}82.5 \% \\
5 \% \\
7.5 \% \\
5 \%\end{array}$ \\
\hline Postoperative hospital stay (days) & $\begin{array}{c}\text { Mean } \pm \mathrm{SD} \\
\text { Range }\end{array}$ & $\begin{array}{c}3.05 \pm 1.26 \\
2-7\end{array}$ & & \\
\hline Cervix by speculum examination & $\begin{array}{c}\text { Normal position } \\
\text { Abnormal position } \\
\text { Hysterectomy/no follow up }\end{array}$ & $\begin{array}{c}32 \\
4 \\
4\end{array}$ & & $\begin{array}{l}80 \% \\
10 \% \\
10 \%\end{array}$ \\
\hline
\end{tabular}


Table 3 shows comparison between patients with placenta previa and patients with placenta previa accreta according to the outcome measures. Mean time needed for technique ( $\mathrm{min}$ ) in cases of placenta previa was $6.90 \pm$
2.25 ; while in cases of placenta accrete, it was $9.10 \pm 2.15$ with statistically significant difference. Intra-operative blood loss was significantly lower with placenta previa cases

Table 3: Comparison between placenta previa and accreta regarding outcome measures:

\begin{tabular}{lcccc}
\hline & $\begin{array}{c}\text { Placenta previa } \\
(\mathrm{n}=20)\end{array}$ & $\begin{array}{c}\text { Placenta previa accreta } \\
(\mathrm{n}=20)\end{array}$ & $\begin{array}{c}\text { Placenta previa accreta } \\
(\mathrm{n}=20)\end{array}$ & $P$-value \\
\hline Time needed for technique (min) & Mean $\pm \mathrm{SD}$ & $6.90 \pm 2.25$ & $9.10 \pm 2.15$ & $0.003^{*}$ \\
Intra-operative blood loss & Mean $\pm \mathrm{SD}$ & $1224.45 \pm 144.80$ & $1457.45 \pm 210.88$ & $0.001^{*}$ \\
Postoperative Hb & Mean $\pm \mathrm{SD}$ & $10.60 \pm 0.77$ & $9.99 \pm 1.06$ & 0.046 (NS) \\
Postoperative hospital stay (days) & Mean $\pm \mathrm{SD}$ & $2.75 \pm 0.79$ & $3.35 \pm 1.57$ & 0.310 (NS) \\
\hline
\end{tabular}

*Statistically significant difference ; NS: no statistically significant difference

\section{DISCUSSION}

Treatment of severe postpartum hemorrhage by uterine or hypogastric artery ligation and arterial embolization is effective, but these approaches can be difficult to perform in practice and the reasons for low use of uterine artery embolization include the small number of modern angiography units with an experienced skilled team on-call 24 hours per day and the perceived risk of transferring a patient in unstable condition to the angiography suite ${ }^{[11]}$. In our study, we present a suture technique which was 1 st described by Dawlatly et al. in a case report in 2007 to control bleeding in cases of placenta previa. The techniques achieve a tamponade-like effect and the bleeding stopped promptly. Three weeks post-partum, the cervix returns to its anatomical position by bimanual palpation and speculum examination $^{[10]}$.

Most of studied patients in a current study have history of previous CS $(80 \%)$ that is in agreement with Silver et al. ${ }^{[2]}$, which is related to the expected association between dramatic increase in the incidence of placenta previa and placenta accreta and the increasing rate of cesarean delivery.

The technique of cervical inversion was successful in stopping the bleeding in 38 out of 40 patients, yielding a success rate of $95 \%$, only two patients had hysterectomy and this is similar to El-Gelany et al. ${ }^{[13]}$ study.

After 6 weeks follow up for the cases, only 38 women from 40 have attended. Speculum examination revealed normal position and normal morphology of the cervix in 32 cases. In four patients, the cervix was displaced upwards, one patient her cervix slightly taken high but with difficult accessibility and in the three patients, the crevices were taken high but with easy accessibility, two patients had not attend the follow up and two patients had hysterectomy, which is slightly different from the postoperative follow up of the cervix in El-Gelany study. Speculum examination after 3 months revealed normal position and normal morphology of the cervix in 33 cases. In two patients, the cervix was displaced upwards, 5 patients did not attend, and two patients had hysterectomy ${ }^{[13]}$.

Mean of intra-operative blood loss in cases of placenta previa was $1224.45 \pm 144.80$; while in cases of placenta accrete, it was $1457.45 \pm 210.88$ which is statistically significant at $p \leq 0.05$. Mean of postoperative hemoglobin in cases of placenta previa was $10.60 \pm 0.77$; while in cases of placenta accrete, it was $9.99 \pm 1.06$ which is statistically significant at $p \leq 0.05$. Current findings are in agreement with Hudon et al. ${ }^{[14]}$, who reported that placenta accreta is associated with more intraoperative blood loss than placenta previa.

Regarding the need of blood transfusion, 7 (35\%) patients of placenta previa need blood transfusion, while $12(60 \%)$ patients of placenta accreta need blood transfusion that is in accordance with O'Brien et al. ${ }^{[15]}$ who reported that most cases of placenta accreta require blood transfusion.

In conclusion, the currently evaluated technique of using the cervix as a natural tamponade to control bleeding caused by placenta previa and focal accreta is apparently safe, simple, rapid and potentially effective. Furthermore, the procedure is easy to perform and does not need specialist skills, materials or equipment can preserve the uterus and future fertility of women with placenta previa and placenta accreta. This technique deserves to be one of the tools in the hands of obstetricians who face the lifethreatening hemorrhage of cases of placenta previa and accreta. Further studies are needed with extended followup of the patients to explore the long-term implications of this technique. 


\section{LIMITATION OF THE STUDY}

The limitation in our study is the presence of diffuse placenta accreta, increta and percreta with severe post-partum hemorrhage diagnosed intraoperatively, as no time for cervical inversion (these cases excluded from our study) and we proceed to emergency hysterectomy. The other limitation is the difficulty of inversion of the cervix in some cases as their cervices were not ripened and not partially dilated and we proceed to other options of conservative management such as transverse B Lunch, internal iliac artery ligation, balloon tamponade and vertical compression sutures. The last limitation is the uncertainty of the effect of the cervical inversion technique on the anatomical and functional capacity of the cervix and its impact on future pregnancy and delivery. However, these worries could be minimized by the promising results of the short and middle term follow-up of these patients

\section{CONFLICT OF INTEREST}

There are no conflicts of interest.

\section{REFERENCES}

1. Garmi G, Salim R. Epidemiology, etiology, diagnosis, and management of placenta accreta. Obstet Gynecol Int. 2012;873929.

2. Vahdat M, Mehdizadeh A, Sariri E, Chaichian S, Najmi Z, Kadivar M. Placenta percreta invading broad ligament and parametrium in a woman with two previous cesarean sections: a case report. Case Rep Obstet Gynecol. 2012;251381

3. Russo M, Krenz EI, Hart SR, Kirsch D. Multidisciplinary approach to the management of placenta accreta. Ochsner J. 2011;11:84-8.

4. Chandraharan E, Rao S, Belli AM, Arulkumaran $\mathrm{S}$. The Triple-P procedure as a conservative surgical alternative to peripartum hysterectomy for placenta percreta. Int J Gynaecol Obstet. 2012;117:191-4.

5. Shao Y, Pradhan M. Intrauterine gauze packing in primary post partum hemorrhage following caesarean section: a clinical study. Nepal J Obstet Gynaecol 2012;7(1):33-6.
6. Fuglsang K, Petersen LK. New local hemostatic treatment for postpartum hemorrhage caused by placenta previa at cesarean section. Acta Obstet Gynecol Scand 2010;89(10):1346-9.

7. Law LW, Chor CM, Leung TY. Use of hemostatic gel in postpartum hemorrhage due to placenta previa. Obstet Gynecol 2010;116 (Suppl. 2):528-30.

8. Nishijima K, Shukunami K, Arikura S, Kotsuji F. An operative technique for conservative management of placenta accreta. Obstet Gynecol. 2005;105:1201-3.

9. Anand AR, Gupta D, Prasad A. Reducing intraoperative lower segment blood loss in placenta previa with Ashok Anand stitch. Int J Reprod Contracept Obstet Gynecol 2013;2(2):135-40.

10. Dawlatly B, Wong I, Khan K, Agnihotri S. Using the cervix to stop bleeding in a woman with placenta accreta: a case report. Bjog. 2007;114:502-4.

11. Ganguli S, Stecker MS, Pyne D, Baum RA, Fan $\mathrm{CM}$. Uterine artery embolization in the treatment of postpartum uterine hemorrhage. J Vasc Interv Radiol 2011;22(2): 169-76.

12. Silver RM, Landon MB, Rouse DJ .National Institute of child health and human development maternal-fetal medicine units network. Maternal morbidity associated with multiple repeat cesarean deliveries. Obstet Gynecol 2006;107:1226-1232

13. El-Gelany S, Abd El-Raheim A, Gad El-Rab M. The cervix as a natural tamponade in postpartum hemorrhage caused by placenta previa and placenta previa accreta: a prospective study. BMC Pregnancy and Childbirth 2015;15:295.

14. Hudon L, Belfort MA, Broome DR. Diagnosis and management of placenta percreta: a review. Obstet Gynecol Surv 1998;53:509-17.

15. O'Brien JM, Barton JR, Donaldson ES. The management of placenta percreta: conservative and operative strategies. Am J Obstet Gynecol $1996 ; 175: 1632-8$ 